\title{
Categorías conceptuales para el estudio de la responsabilidad social organizacional ${ }^{\star}$
}

\author{
Carlos Tello Castrillón ${ }^{* *}$ María del Pilar Rodríguez Córdoba
}

\begin{abstract}
Recibido: 28 de febrero de 2014
Evaluado: 12 de abril de 2014

Aceptado: 10 de mayo de 2014
\end{abstract}

\section{Resumen}

El crecimiento del poder económico y político de las corporaciones multinacionales, junto a la interconexión entre mercados locales y el mercado global, ha erigido a la Responsabilidad Social Corporativa como elemento central en el control de sus actividades, especialmente aquellas que escapan a las regulaciones locales. No obstante, los conceptos alrededor del tema adolecen de vaguedades que los hacen difusos, y por tanto difíciles de aplicar y auditar. Éstas terminan por convalidar como responsabilidad social prácticas que bajo un análisis más detallado no corresponderían a su verdadero espíritu moral. Bajo un enfoque hermenéutico, partiendo del replanteamiento de la Responsabilidad Social Corporativa para entenderla como Responsabilidad Social Organizacional, este escrito estudia tales vaguedades conceptuales, sus limitaciones y contradicciones en la aplicación. En la parte final, se proponen algunos elementos teóricos, que se concentran en reducir la voluntariedad en la asunción de la Responsabilidad Social Organizacional. En su lugar, se promueven mayores regulaciones estatales, en tanto representaciones de la sociedad, y una mayor conciencia de las organizaciones para la revisión de sus procesos productivos. Se aboga por la inclusión, en todo momento, del concepto de ciclo de vida ambiental en los procesos productivos organizacionales, de tal manera que se conviertan en organizaciones socialmente responsables con un sentido claro de la sostenibilidad.

Palabras clave: responsabilidad Social, corporaciones, regulación estatal, teoría organizacional, grupos de interés.

Artículo de reflexión. Éste hace parte de la primera fase de la revisión teórica hecha para el trabajo doctoral del autor principal, en el cual se relacionan la Responsabilidad Social Organizacional y el Gobierno Corporativo en las Multilatinas. La coautora ejerce como directora del trabajo. Cómo citar este artículo: Tello Castrillón, C., \& Rodríguez Córdoba, M. (2014). Categorías conceptuales para el estudio de la responsabilidad social organizacional. Hallazgos, 11 (22), pp. 119-135.

** Candidato a Doctor en ingeniería, industria y organizaciones. Universidad Nacional de Colombia Sede Manizales. Profesor asociado Universidad Nacional de Colombia Sede Palmira. E-mail: catelloca@unal.edu.co, dirección Postal: K32 12-00 Dpto. de Ciencias Sociales. Palmira-Valle (Colombia).

*** Ph. D. Universidad de Bradford, Inglaterra. Profesora titular Universidad Nacional de Colombia Sede Manizales. E-mail: mdrodriguezc@unal.edu.co Dirección postal: Campus La Nubia. Dpto. de Ingeniería Industrial. Manizales-Caldas (Colombia). 


\section{Conceptual categories of the study organizational social responsibility}

\section{Abstract}

The growth of the economic and political power of multinational corporations, along with the interconnection between local and global markets, has raised Corporate Social Responsibility as central element in the control of their activities, especially those that escape local regulations. Nevertheless, concepts about that topic suffer vagueness that make them diffuse, and therefore difficult to execute and to audit. These vagueness consider as Social Responsibility, practices that otherwise, under a more detailed analysis, would not correspond to its truly moral spirit. Under hermeneutical view methodology, this paper shifts from Corporate Social Responsibility concept to Organizational Social Responsibility, and studies its conceptual vagueness, limitations and contradictions in execution. Final part, shows some proposed theoretical elements, which focus on reduction of the voluntary assumption of the Organizational Social Responsibility. It is shifted to an increasing Government regulation, since Government plays the role of society representation, and a bigger Organizations conscience for reviewing its productive processes. It is necessary to include at any time the environmental life cycle concept in such productive processes, so they become socially responsible Organizations with a clear sense of what sustainability is.

Keywords: Social Responsibility, state regulation, organization theory, stakeholders, corporations. 


\section{Categorias conceituais para o estudo}

\section{da responsabilidade social organizacional}

\section{Resumo}

O crescimento do poder econômico e político das empresas multinacionais, junto com a interligação entre os mercados locais e o mercado global, têm erguido à Responsabilidade Social Corporativa como um elemento-chave no controle de suas atividades, especialmente aquelas que vão além das regulamentações locais. No entanto, os conceitos em torno do tema têm falta de claridade ou de exactidão que o tornam turvo, e, portanto de difícil aplicação e auditoria. Eles acabam validando como Responsabilidade Social, práticas que sob uma análise mais aprofundada não correspondem ao seu verdadeiro espírito moral. Sob uma abordagem hermenêutica, baseada na reformulação da Responsabilidade Social Corporativa para endente-la como Responsabilidade Social Organizacional, o artigo estuda tais ambigüidades conceituais, suas limitações e contradições na aplicação. Na parte final, propõem-se alguns elementos teóricos que se concentram em reduzir à voluntariedade na assunção da Responsabilidade Social Organizacional. Em vez disso, são promovidos mais regulamentos estatais, no entanto representações da sociedade, e uma maior consciência das organizações a rever seus processos de produção. Procura-se pela inclusão, em todos os tempos, do conceito do ciclo de vida ambiental nos processos de produção organizacionais, para que se tornem organizações socialmente responsáveis, com um claro sentido de sustentabilidade.

Palavras-chave: Responsabilidade Social, teoria organizacional, grupos de interesse, corporações, regulação estatal. 


\section{INTRODUCCIÓN}

La promoción de la responsabilidad social corporativa (RSC) ha sido trabajada con especial énfasis desde los años 60. Su intensidad ha venido en aumento, y hoy día es un tema recurrente, dadas las mayores interconexiones globales que llevan a una creciente interdependencia socio-económica entre los países. Como manifestaciones de esto último, aparece la proliferación de las corporaciones multinacionales, junto a otros agentes económicos globales, en la mayoría de mercados locales del mundo. Debido a su amplitud, la actividad de estos agentes se escapa de las auditorías locales, haciendo necesario otro tipo de controles de corte internacional y de autorregulación. En este nuevo escenario, la RSC se ajusta muy bien como una nueva forma de control y autorregulación; sin embargo, actualmente ella ha pasado a ser un imperativo que, no obstante su trayectoria, no cuenta con la suficiente claridad en su cuerpo conceptual.

Los significados que definen la RSC aún son imprecisos y, por tanto, en algún grado problemáticos. Una primera razón para ello es justamente su asociación a las grandes corporaciones. Así, no parece importante la existencia de responsabilidad social (RS) en los actos de las restantes organizaciones: Mipymes, sin ánimo de lucro y estatales. Pero basta recordar la presencia de grupos de interés (GI) en cualquiera de éstas, para evidenciar que la RS atañe a cualquiera que sea la organización. Concomitantemente, tal apariencia hace inseguro el hecho de que la RSC sea de ineludible asunción en toda organización para todo momento. Una segunda razón que explica la problemática, reposa en el hecho de que las definiciones imprecisas no delimitan los actos que realmente pertenecen a la esfera de la RSC.
Este escrito asegura que la RSC es incompleta como concepto y, por eso, propone reemplazarlo por el de responsabilidad social organizacional (RSO). Desde esta perspectiva, se concibe que la sociedad está articulada por una red de organizaciones. Por tanto, los actos de RSO deben estar bajo la reglamentación y regulación del Estado.

Por tratarse de un artículo de reflexión, no se puede hablar de una metodología propiamente dicha; sin embargo, es claro que este tipo de escritos se elaboran bajo un enfoque hermenéutico, el cual permite la interpretación y creación de conceptos propios de la reflexión.

La primera parte del escrito argumenta el cambio desde la RSC hasta la RSO. Posteriormente, aborda sus ambigüedades conceptuales y los consiguientes efectos nocivos sobre sus estudios y aplicaciones. Al final de la sección, se proponen unos breves elementos para un mejor entendimiento del concepto de RSO. En la segunda parte del escrito, se presentan las limitaciones deductivas, fronteras del alcance de la RSO tal como está concebida y las contradicciones entre la acepción común de RSO y sus principios fundamentales. En la conclusión, se exponen los elementos que configuran una visión de RSO tal que lleva a las organizaciones a incluirla como parte ineludible de su actividad. Esto bajo la observancia permanente de las imbricaciones que tienen aquellas en el tejido social.

\section{LA IMPRECISIÓN DE LOS TÉRMINOS DE LA RSC}

La responsabilidad social corporativa (RSC) como categoría conceptual es imprecisa (Koslowski, 2008), y debido a esto se hace 
difícil tanto su estudio como la auditoría de las acciones empresariales socialmente responsables. Este apartado tiene como propósitos: a) extender el concepto de RSC hasta el de responsabilidad social organizacional (RSO); b) resaltar la inconveniencia de la ambigüedad en las definiciones de RSC; y c) proponer nuevos elementos para una definición más precisa de RSO, en la cual se incluya al Estado.

\section{El ARribo de LA RSC}

Las definiciones de $\mathrm{RSC}^{1}$ en su sentido original aluden al compromiso retributivo que tienen las corporaciones frente a su entorno inmediato, a su mesoentorno y al entorno general, como forma de compensar las ganancias obtenidas. "En su nivel más general la RSC trata de la relación entre los negocios y la sociedad" (Jenkins, 2009, p. 69). Esta definición es similar al significado de RS, que sirve de base para el escrito crítico de Fougère y Solitander (2009, p. 217), en el que se plantea la RS como mediadora entre el "desarrollo sostenible y el liberalismo de libre mercado". Por ser la comunidad - representada en el entorno- la que aprueba o desaprueba la gestión corporativa, el significado de RSC es alusivo a las relaciones sociales (Enderle, 2010) en todo momento y lugar.

Para Jenkins (2009), la RSC es un concepto, aunque parcialmente cambiante según se trate de tal o cual autor, o actor social, que se caracteriza por ser voluntario, excedente frente al mínimo legal enfocado a las empresas, interesado en todos los grupos de interés (GI) y, centrado en la famosa triple línea de base de lo económico, lo social y

1 Más adelante se reproducirán algunas de ellas. lo medio ambiental (Carroll, 1979). La RSC cambia su énfasis de acuerdo al nivel de desarrollo de un país. En los países desarrollados tiende hacia lo sostenible, mientras que en los países en vías de desarrollo, enfatiza la lucha contra los problemas de corrupción de los agentes privados y estatales (Méndez Picazo, 2005). Ella parece ser un producto de las preocupaciones de los países con sociedades civiles más fuertes, como Europa occidental y EE.UU. (Egri \& Ralston, 2008), las cuales tienen la capacidad de presión y bloqueo de aquellas corporaciones con prácticas anti-RSC.

El auge actual de la atención a la RSC sobreviene por el gran crecimiento de las corporaciones multinacionales (Ungericht \& Hirt, 2010). Su forma original está referida a este tipo de organizaciones (Jenkins, 2009; Assländer, 2011), así como su capacidad de operar en los distintos escenarios civiles, a los que llega en busca de ventajas competitivas. Este hecho, origina la pérdida del control que recae sobre ellas desde los Estados Nación, y desde las sociedades civiles en general. En algunos casos, el poder económico y político de esas multinacionales es superior al de muchos Estados como tales, llegando incluso a convertirse en supra Estados. La debilidad en el control, las habilita para, eventualmente, evadir las regulaciones y cometer actos en contra del bienestar general. Una forma de aliviar ese problema sería un comportamiento RSC, que vendría a operar como un auto-control corporativo para atenuar aquellos actos. La predilección de las corporaciones hacia la autorregulación nace sobre la base de conservar su autonomía. Esto no es un fenómeno reciente, de hecho el nacimiento de la RSC es muy anterior a su auge corriente. Como cualquier 
fenómeno social, sus orígenes se remontan atrás en el tiempo.

El "nuevo modelo de empleadores entre 1850 y 1860 en Inglaterra y el movimiento del mejoramiento industrial en E.E.U.U. durante el último cuarto del siglo XIX" (Jekins, 2009, p. 69) parecen ser los antecedentes sociales primarios de la RSC. Es lógico tomar estos referentes, toda vez que la gran corporación solo emerge después de la revolución industrial de finales del siglo XVIII y comienzos del XIX. En esta época, cita Jenkins (2009), en la planta textil de Robert Owen, se trataba de respetar la integridad física del obrero en su lugar de trabajo, en la que tal vez sea la primera referencia individual de RSC. Por su parte Taneja y otros consideran que la RSC surge en 1932 cuando Merrick Dodd publica “¿para quién son las gestiones de los administradores corporativos?" (Taneja, Taneja, \& Gupta, 2011).

Ya en la época contemporánea, la década de los 60 y 70, se presenciaron los escándalos políticos que involucraban corporaciones con prácticas de lobby y publicidad engañosa. A esta fase Jenkins la llama la primera ola de RSC (2009, pp. 69-70). A partir de los 90, especialmente después de la cumbre de Rio de 1992, el énfasis de la RSC recae en la sostenibilidad. Esta segunda ola es encabezada por Europa y abarca también las condiciones laborales y los derechos humanos. La fortaleza de la RSC en la actualidad obedece a la rápida difusión de la información entre las distintas sociedades civiles, las cuales ejercen cada vez más presión sobre las corporaciones cuyos actos consideran lesivos.

Las corporaciones son los nuevos actores políticos en un mundo globalizado que ya no es controlado por las regulaciones de las naciones estado pero si por la presión de los GI y las campañas de acusación o las amenazas de boicots de las ONGs. (Assländer, 2011, p. 122)

En este escenario, la primera respuesta esperable es el reforzamiento de las reglas internacionales, pero es lógico pensar que la reacción de las corporaciones sea acudir al discurso autorregulatorio.

Analizando los elementos generales anteriormente citados, es evidente que la RSC no es un asunto que concierna estrictamente a las corporaciones. Esto es corroborado por Taneja y otros, para quienes este concepto cubre a cualquier organización (2011). Dos razones sirven para justificar tal afirmación. Las organizaciones - empresas o no empresas - pequeñas y medianas, y en general todas las no corporaciones, también hacen parte de las mismas redes societales en las que están presentes las grandes corporaciones. De igual manera, cada una de ellas cuenta con las respectivas muestras de sus distintos GI. Pero, el asunto va aún más allá. La RSC tampoco es un contenido vinculado unívocamente a las empresas, puesto que esta expresión solo arropa a las unidades de negocio u organizaciones con ánimo de lucro. Cualquier organización, empresa o no, tiene obligaciones sociales con sus empleados, proveedores, clientes, su comunidad y también con el nivel societal. De ahí que RSC sea un concepto corto frente a tal extensión de relaciones, por tanto debe ser ampliado para que se identifique como RSO. En adelante, este último será el término empleado en este escrito, reemplazando las expresiones RSC y Responsabilidad Social Empresarial. 
La RSO, en tanto acto de interacción social entre agentes sociales libres que ejercen su discrecionalidad, es susceptible de manejarse a través de dinámicas semejantes a los Mecanismos de Mercado. Aquí se espera que sea la libre interacción entre los agentes, la que lleve a los resultados colectivamente deseables, bajo condiciones de fluidez de recursos e información (Tello Castrillón, 2006). Pero, al igual que sucede con los productos en un Mercado, la RSO no es homogénea, ni en sus acciones ni en sus motivos. Es por ello que se espera que el Estado actúe, para arbitrar las relaciones entre los GI, especialmente defendiendo los intereses de aquellos grupos con menor visibilidad o menor capacidad de cabildeo. Esto va muy de la mano con la promocionada tercera vía, que defiende la premisa de tanto Mercado como sea posible, tanto Estado como sea necesario, la cual podría re interpretarse como tanta RSO discrecional como sea posible, tanta RSO mediada como sea necesario. Por eso es que las nuevas tendencias de estudio de la RSO apuntan a enfocarla como un asunto de Gobernanza, donde el Estado justamente cumple un papel más de mediador que de regidor (Moon, 2004). Aún con la participación del Estado, cabe esperar que los poderes de las grandes corporaciones, para influir en las regulaciones y acciones estatales frente a la RSO, sean muy superiores a los correspondientes en las pequeñas empresas.

\section{LAS IMPRECISIONES EN LA DEFINICIÓN DE RSO}

Ante la proliferación de enfoques y estudios sobre la RSO, especialmente en los últimos veinte años, han surgido muchas definiciones, articulaciones y perspectivas que la hacen un concepto difícil de unificar. Esto entraña un inconveniente mayor, que consiste en la dificultad de comparar estudios y acciones de RSO surgidos desde distintos ámbitos, a lo que se suma la ausencia de una metodología predominante (Taneja, Taneja, \& Gupta, 2011; Randall \& Gibson, 1990). Al final, es la capacidad hermenéutica del investigador la principal herramienta para marcar tendencias generales, dentro de un espectro de estudios específicos. Varios autores lamentan tales imprecisiones (Assländer, 2011; Taneja, Taneja, \& Gupta, 2011; Enderle, 2010; Jenkins, 2009; Melé, 2007; Vargas Nie1lo, 2006), al tiempo que hacen parte de ellas. Por ejemplo, para algunos la RSO está circunscrita a la ética de los negocios(Assländer, 2011; Enderle, 2010; Ungericht \& Hirt, 2010), mientras que para otros es un asunto de Ciudadanía empresarial (Carroll, 1979). Estas asociaciones se suman a las subsumisiones o suplantaciones de la RSO con la rendición social de cuentas, la filantropía, la teoría de los GI, y la actuación social empresarial (Taneja, Taneja, \& Gupta, 2011). Hasta el momento, no ha sido posible consolidar una definición típica de RSO que sirva como una especie de axioma fundacional y que guíe sus investigaciones.

Las definiciones más difundidas de RSO indican imprecisamente un genérico de lo que debe hacer una empresa para cumplir con su responsabilidad social, sin aclarar el por qué lo debe hacer. Así pues, la RSO es señalada como una propuesta esencialmente normativa y menos descriptiva (Enderle, 2010; Melé, 2007), a la usanza del Management. Tales definiciones recalcan la voluntariedad del acto de RSO (Ungericht \& Hirt, 2010), tanto en su emprendimiento como en la selección de las formas de ejecutarla. Tal imprecisión y tal voluntariedad hacen de la RSO un acto 
mayoritariamente - respecto a los otros agentes sociales - ligado a la discrecionalidad organizacional, lo cual se acentúa con el hecho de que, en general, el impacto de los actos RSO no está referido a un patrón esperado.

Una revisión de aquellas definiciones da cuenta de esta afirmación, donde inicialmente se destaca la postulada por la Comisión Europea, que quizás sea la concepción de RSO más utilizada y reseñada:

La Responsabilidad Social de las empresas es, esencialmente, un concepto con arreglo al cual las empresas deciden voluntariamente contribuir al logro de una sociedad mejor y un medio ambiente más limpio. (Comisión de las comunidades europeas, 2001, p. 4). ${ }^{2}$

El texto donde aparece esta consideración se conoce como el Libro verde, en él se liga la RSO con otros conceptos generales, como los derechos humanos, el conocimiento y la transparencia, y con organizaciones internacionales.

Las categorías conceptuales allí aludidas son de tal amplitud que permiten incluir muchos actos como contribuyentes a la RSO. En algunos casos, dichos actos podrían ser genuinas ejecuciones sociales, p.e. la descontaminación de un río no aledaño a la organización, pero en otros casos, podría tratarse de simples juegos nominativos para realizaciones en ciertos aspectos, que disfracen la falta de compromiso social en otros. Este fue el caso de algún supermercado que se promocionaba como impulsador de la mano de obra regional, al tiempo que no pagaba salarios a sus empacadores de caja.

2 Se agregó el énfasis.
La situación solo cambió cuando el Estado obligó a regularizar la condición laboral de estos últimos.

Otra definición de RSO de amplia cobertura es la generada por el Consejo Empresarial Mundial para el Desarrollo Sostenible (WBSCD, por su sigla en inglés), toda vez que cobija a 160 empresas de alcance global. Para éste, la RSO actúa "vía los tres pilares de crecimiento económico, el balance ecológico y el progreso social" (The business case for sustainable development WBCSD, 2002, p. 15) y se define como:

El compromiso de los negocios con la contribución al desarrollo económico sostenible, trabajando con los empleados, sus familias, la comunidad local y la sociedad en general para mejorar su calidad de vida. Así las preocupaciones por el ambiente son parte de la RSO de la empresa. La RSO es un concepto fundamental como la libertad o la igualdad. Este debe estar siempre siendo redefinido para servir a las necesidades y tiempos cambiantes (WBCSD, 2002, p. 6). ${ }^{3}$

Visto de esta forma, al mismo nivel de la libertad, la RSO es casi una base ontológica de la conducta social, y con esta afirmación se convertiría en un comportamiento simplemente imposible de eludir. Al final, todas las organizaciones se comportarán en algún grado, a veces más y a veces menos, socialmente responsables. Es lógico pensar que las definiciones de RSO abogan por comportamientos altamente responsables. La siguiente pregunta, entonces, debería ser ¿cuáles son los actos concretos que se engendran a

3 Se agregó el énfasis. 
partir de este comportamiento? La definición indica que son las preocupaciones por el ambiente y las necesidades ... cambiantes. Ambos son conceptos muy indefinidos y laxos, y abren la puerta para que ejecuciones pequeñas e intrascendentes también calcen como actos altamente responsables.

Una muestra de las ambigüedades del término RSO se puede encontrar en las cuatro perspectivas de Jenkins (2009) y que se muestran en la Tabla 1. Las imprecisiones en la medición de los efectos de los actos RSO (Assländer, 2011; Taneja, Taneja, \& Gupta, 2011; Fougère \& Solitander, 2009) hacen que todas esas perspectivas sean válidas, aunque virtualmente excluyentes entre sí. Es decir, que ninguna podría considerarse más acertada que otra. Este autor propone dos ejes temáticos para determinar las categorías, ambos se refieren a la bondad o perversidad del impacto de la RSO: sobre la ganancia de la organización en uno de ellos $y$, sobre la sociedad en el otro eje. Para hacer las consideraciones de Jenkins extensivas a cualquier organización, se puede relativizar la alusión a la ganancia contenida en la expresión negocio (business) que él usa, tratándola como excedente genérico de cualquier ejercicio organizacional.

Tabla 1. Contraste de perspectivas en RSO

\begin{tabular}{|c|c|c|c|}
\hline & & \multicolumn{2}{|c|}{ IMPACTO EN LOS NEGOCIOS } \\
\hline & & Aumenta ganancias & Reduce ganancias \\
\hline \multirow{2}{*}{ IMPACTO EN LA SOCIEDAD } & Bueno & Caso de negocio & Robín Hood \\
\hline & Malo & Consentimiento ingenieril & Libertaria \\
\hline
\end{tabular}

Fuente: Jenkins (2009, p. 71).

La perspectiva más mediática de RSO es llamada el caso de negocio (business case). Según ésta, mediante la RSO, la organización establece una relación gana-gana con la sociedad. La definición de RSO del WBSCD es explícita en asumir esta posición. La versión más radical de esta perspectiva se encuentra en Friedman (1970), para quien la organización cumple con su RS a través del pago de impuestos y la sujeción a las leyes, pero ante todo con la generación de ganancias para sus accionistas, en tanto representantes de la sociedad. Es más atenuada la posición de Drucker (1984) al respecto, toda vez que reconoce la organización como parte integral del tejido social, aunque sin dejar de preponderar la ganancia como su fin supremo.
Tal como cualquier otro caso de negocio, la incorporación de la RSO en la actividad organizacional depende de su relación costo beneficio. Este último se representa especialmente en el posicionamiento de la organización en el mercado. Del posicionamiento depende la lealtad de clientes y accionistas actuales, y el atractivo de la organización frente a los nuevos; esto la obliga a no abandonar su búsqueda de eficiencia. Por ejemplo, el componente ambiental de la RSO - y en general los demás componentes - pasa a ser un factor que "promueve la innovación y la competitividad" (Jenkins 2009, p. 71).

Una versión menos optimista que la del caso de negocio supone que la sociedad, y no 
la organización, es la única que gana con la RSO. Esto se debe a que las inversiones para cumplir con las obligaciones de RSO al final significan una transferencia de recursos desde los accionistas organizacionales hacia los otros GI. Jenkins (2009) llama Robin Hood a esta perspectiva, según la cual los administradores organizacionales se distraen de su objetivo primario de lucro, por atender asuntos de la triple línea de base que son ajenos a la naturaleza de su función. De esta manera, la RSO solo puede ser ejercida por aquellas organizaciones con la suficiente robustez financiera, para asumir las erogaciones que ella implica; lo que hace menos plausible que empresas micro, pequeñas y medianas se comprometan con ello.

Las últimas dos perspectivas serán ampliadas más adelante en el apartado dedicado a las críticas a la RSO, por su cercanía conceptual con otros postulados cuestionadores del tema. Basta decir, por ahora, que en el consentimiento ingenieril, la RSO es vista como una simple forma incompleta de compensación a la sociedad. Esta compensación se hace pensando en hacer furtivos los daños que la organización genera. De esta manera, ella se ahorra los costos de hacer su actividad sostenible y amigable con su entorno, por lo que al final ocurre una transferencia de estas cargas hacia la sociedad. La visión plenamente negativa de la RSO se consigna en la perspectiva Libertaria, que asume que la RSO es indeseable para la sociedad y la organización. Esto se debe a que aquélla implica costos intra-organizacionales de implementación, y distorsiona la competencia y el libre ejercicio empresarial.

Las mayores preocupaciones y avances investigativos sobre la RSO, se han dado en su impacto financiero y de mercadeo (Taneja, Taneja, \& Gupta, 2011; Egri \& Ralston, 2008), lo que demuestra que la mayor concentración de las propuestas de RSO, recaen en lo intraorganizacional, dejando entrever un manejo de la RSO como elemento de mercadeo, en tanto instrumento de posicionamiento. Ante ello, varios autores reclaman una mayor investigación en las formas de medición y seguimiento del impacto de los actos de RSO, no sólo sobre la organización misma sino sobre la Sociedad en general (Taneja, Taneja, \& Gupta, 2011; Fougère \& Solitander, 2009; Assländer, 2011; Moon, 2004). Esto significa que la investigación sobre RSO, debe acercarse más a los estudios macroeconómicos y de políticas públicas (Assländer, 2011; Ungericht \& Hirt, 2010; Moon, 2004).

En tal sentido, Assländer (2011) plantea razones cercanas a las relaciones societales de la organización, para entender por qué son incompletas las formulaciones sobre la RSO:

1. Existen dos tendencias generales en RSO. Una es la estadounidense dirigida hacia la filantropía y la ética en los negocios. La otra tendencia es de origen europeo, que se concentra en la triple línea de base y lo sostenible. Los actos filantrópicos son menos protagonistas en el viejo continente debido a que el Estado de Bienestar se siente con mucha intensidad.

2. Existen motivaciones distintas para que las organizaciones asuman la RSO. Estas pueden radicar en el verdadero compromiso ético (es decir que no necesita justificación porque es orientado por la buena voluntad), en su utilidad como instrumento de estrategia 
de mercadeo o en su conveniencia para lidiar los asuntos políticos y de gobierno corporativo (Arora \& Dharwadkar, 2011; Sacconi, 2012).

3. La proliferación de términos, asociaciones y subsumisiones referidas arriba obedece a que la visión de la RSO está demasiado cargada a la organización y

Es más problemático que la RSO no tenga la teoría política correspondiente que permita integrarla en un concepto macroeconómico y así definir las responsabilidades corporativas desde una perspectiva gubernamental. (Assländer, 2011, p. 117)

Si se mira con detenimiento el cumplimiento de la RSO por parte de la organización, significa proveer servicios - ocasionalmente bienes también - que aporten a la sostenibilidad de la sociedad decir, que con esto la organización asume, parcialmente, funciones tradicionalmente asumidas por el Estado, y que por alguna razón éste no cumple. Sin embargo, está pendiente la delimitación y articulación de la organización socialmente responsable con el Estado. Para tal cometido, como punto de partida, se hace relevante definir hasta dónde es suficiente que la RSO sea un acto enteramente voluntario, basándose en:

a. El ineludible papel organizacional como mediador entre la comunidad que la alberga y el Estado y,

b. Los impactos extra misionales de la actividad organizacional sobre todos sus GI.
La superación de las imprecisiones de la RSO puede abordarse escindiéndola en al menos dos momentos distintos: hay unos rasgos propios del momento de la asunción de la RSO y, otros del momento de su ejecución. En el primer momento, cuya naturaleza es más cualitativa, se pueden incluir las razones que llevan a que una organización, la sociedad civil o el Estado se involucren en acciones RSO, bien sea desde su oferta o desde su demanda. Esto implica remontarse hasta los orígenes ontológicos de la responsabilidad y lo público, para luego llegar a la fenomenología de la RSO. Esta última es la versión más difundida, tal como frecuentemente sucede con las disciplinas fácticas de estudio en estadio temprano de maduración.

En el segundo momento se hace necesario definir, con alto grado de precisión, cuál es el impacto esperado, expresado en cobertura y sostenibilidad de las acciones organizacionales, para que puedan ser catalogadas como verdaderos hechos de RS. De esta manera, se evitaría que pequeñas dádivas dejen de ser promocionadas como elementos de naturaleza RSO. Este momento requiere de mayores elementos cuantitativos para su estudio, debe ir de la mano con el impulso de la RSO, desde los procesos internos de las organizaciones, en especial con la formación de los sujetos organizacionales.

\section{LiMitACIONES DE LA RSO}

Tal como se había mencionado, los actos RSO se orientan a la provisión de servicios, usualmente asumida por el Estado. Esta premisa es necesaria para entender cómo las propuestas sobre RSO están sujetas a varias limitaciones, previstas desde lo conceptual. 
En algunos casos, éstas son fruto de las deducciones argumentativas que surgen de sus postulados, mientras que en otros, provienen de las ambigüedades ya señaladas.

En esta parte del escrito se expondrán algunas limitaciones de la concepción de la RSO. Se parte de la aceptación de sus argumentaciones, para luego desarrollar conclusiones. Por eso, se llaman limitaciones deductivas, y son resultado de la no contradicción del pensamiento de RSO. La parte final de esta sección recoge algunas críticas, de la manera en que se ha venido trabajando la RSO, presentadas bajo la forma de contradicciones que señalan la no coincidencia entre la ontología de la RSO y las manifestaciones de su realización.

La primera limitación deductiva es la señalada por Assländer, para quien es contradictoria la concepción de que los gobiernos vean la RSO como un acto voluntario de las organizaciones, mientras que éstas la ven como una presión social. Esto es una consecuencia del tratamiento de las organizaciones como "actores cuasi gubernamentales" (Assländer, 2011, p. 118), recalcado por las prescripciones del Libro verde, las guías OECD, el Pacto global de la ONU y la ISO 26000 (Assländer, 2011). Tal condición les confiere una gran discrecionalidad, en simultánea con grandes obligaciones hacia la comunidad; la discrecionalidad justifica la RSO como acto voluntario, mientras que, por otro lado, las prescripciones configuran las presiones sociales para que las organizaciones asuman la RSO.

Las organizaciones socialmente responsables, ostentan dos relaciones significativas con su comunidad, por una parte, le amplifican sus demandas y por otra parte le proveen servicios cuasigubernamentales. Por tanto, la RSO debe ser incorporada en el manejo de la gobernanza estatal, sin que el Estado aguarde a que sean sólo ellas, bajo las ineludibles lógicas de lucro organizacional, las que encaucen sus actos de RSO. Sin embargo, una segunda limitación deductiva controvierte esta posibilidad.

La posición de Drucker (1984) es distante, respecto a la incorporación de la RSO en la gobernanza estatal. La organización no dispone ni de los instrumentos ni de la amplitud de acción, de los que sí dispone el Estado. De ahí se puede inferir que las acciones de estos dos no sean comparables. Según este razonamiento: que la organización asuma obligaciones sociales de gran escala es una labor inútil y costosa, ella, por tanto, cumple funciones sociales sólo en pequeña escala, puesto que nadie mejor que el Estado como tal para ejercer acciones de verdadero alcance macro social. Esta visión limita y exonera a la organización de gran parte de las responsabilidades sociales - del mismo tipo de los servicios cuasi gubernamentales-, no obstante, que la reconoce como parte integral de la sociedad.

La dicotomía voluntariedad - presión, en la asunción de la RSO, viene tamizada por otra dicotomía que da cuenta del verdadero compromiso social de la organización: la RSO sujeta a los excedentes del ejercicio organizacional vs. la RSO libre de esa sujeción. La utilización de la RSO como instrumento para la legitimación social con fines de mercadeo aparece como una acción posganancia. Así, la RSO es residual y asume la forma de "actividades filantrópicas" o de "donaciones caritativas". Un compromiso social 
pleno debería afectar la ganancia conseguida y no ser una inversión condicionada; esto es, en un sentido ideal, la versión pura de RSO se asumiría "pre ganancia" (Jenkins, 2009, p. 69).

La siguiente limitación reside en las relaciones de la RSO con lo macrosocial y lo macroeconómico. Éstas son las partes menos fáciles de medir, dada su multidimensionalidad. Una superposición de la lógica económica y la lógica de la RSO permite pensar que se puede crear poder de mercado apalancado en las erogaciones para RSO, a través del reforzamiento de posiciones oligopólicas o monopolísticas. Siendo esto así, y dada la citada dificultad de medición, el monto absoluto de las erogaciones parece ser suficiente para posicionar mejor a una organización que a otra.

En este sentido, se descuidaría la proporcionalidad de la erogación en RSO, respecto al tamaño de la organización, y más importante aún, respecto a los impactos negativos ambientales y sociales que pueda generar, partiendo de que el cumplimiento de la RSO exige erogaciones desde las organizaciones, aquellas que hagan las mayores inversiones a partir de su robustez financiera entonces serán las más apreciadas por el mercado. Pero en realidad, grandes inversiones no siempre significan mayor RS. Una organización pequeña podría ser socialmente más responsable que una gran organización, si por ejemplo cobija y/o impacta más GI propios que los que cubre la segunda. Es por esto que la RSO altera las relaciones de competitividad, y se erige como una nueva forma de barreras de entrada a un sector (Jenkins, 2009). Por supuesto, esto impide la llegada de pequeños ofertantes y captura rentas para los competidores establecidos.
Dentro de la dificultad de seguimiento de los efectos de los actos RSO sobre el entramado social, son más factibles de auditar aquellos correspondientes a lo financiero y a lo laboral. La tarea se facilita, pues se trata de campos con indicadores relativamente precisos. Por ejemplo, en el segundo campo, la RSO ha sido muy útil en la mejora de las condiciones laborales y en la eliminación del trabajo de los niños, aunque no ha tenido la misma acuciosidad en la difusión del derecho del obrero a asociarse (Jenkins, 2009). Pero el impacto sobre la complejidad y heterogeneidad del resto del conjunto societal es más complicado de evaluar. Esto surge de la dificultad que se tiene, en el terreno social, para aislar y observar los efectos de una acción a lo largo de todo el tejido. Las observaciones que eventualmente se puedan hacer sobre un grupo objetivo, no son suficientes para hacer lo propio con el resto de la sociedad. Jenkins opina que "la falta de investigaciones sistemáticas en los impactos sociales y ambientales de la RSO refleja las dificultades inherentes al análisis de tales impactos" (2009, p. 74).

Las mayores limitaciones deductivas de la RSO se reflejan en los impactos negativos previstos en el cuadrante de Jenkins referido atrás, los cuales son llamados por el autor "El consentimiento ingenieril" y la "Libertaria" (Jenkins, 2009, p. 71). En la primera, la RSO es vista como un distractor que cubre con pequeños actos de greenwash (la mezcla de Green y Brainwash que significa lavar el cerebro con pequeños actos sostenibles) a los impactos negativos sociales y ambientales más fuertes de la organización. La distracción se configura con una larga retórica y poca acción real. Bajo esta lógica, los controles estatales son evitados por medio 
del discurso de la autorregulación. Análogamente, puede suceder con la disminución del poder de asociación de los trabajadores, a partir de la promoción de buenas prácticas laborales. La posición libertaria es definitivamente la más pesimista del cuadrante, pues asume que la influencia de la RSO en la organización y la sociedad, es negativa en ambos casos. La RSO significa un gasto inútil para la organización dada su escasa repercusión social, y al final resulta en una obstrucción a la naturaleza competitiva del mercado.

Todas las limitaciones deductivas anteriores: la organización en cuanto organismo cuasigubernamental, la dicotomía voluntariedad-demanda, el corto alcance relativo de las acciones de la organización, la multidimensionalidad, la distorsión de la competencia y la dificultad de seguimiento del radio de los actos RSO, más el hecho de que la RSO hoy día no es un postulado exclusivo de las grandes corporaciones (Taneja, Taneja, \& Gupta, 2011) hacen que el tratamiento de la RSO como acto preganancia y voluntario se quede corto. Debido a los entrecruces organizacional-societales es creciente la presión por la regulación legal de la RSO desde el Estado (Assländer, 2011; Moon, 2004), que debe ir acompañada por sociedades civiles más fuertes que funcionen como elementos de presión y vigilancia. De no ser así, la primacía de la ganancia sobre las otras consideraciones organizacionales terminaría por hacer eludir, cuando sea necesario, compromisos de RSO. Este es el tema a explorarse en el próximo apartado.

En la última parte de esta sección, se presentan algunas contradicciones subyacentes en la realización de la $\mathrm{RSO}$. Se asume que el constructo teórico básico de la RSO, permitiría que estas contradicciones fueran superadas, puesto que son resultado del impreciso tratamiento que se le ha dado a aquél constructo, sin embargo, ellas nacen justamente del distanciamiento entre el constructo teórico básico y la realización de la RSO.

La RSO es acusada, como ya se ha venido mostrando, de ser una herramienta de posicionamiento en el mercado, que se puso de moda ante las presiones de la sociedad civil. La deslegitimación de la actividad organizacional es una amenaza para el mantenimiento de los clientes y para el atractivo de la organización ante potenciales accionistas o aliados, es decir que atenta contra la propia existencia de la organización. En respuesta a ello, la RSO sirve para "anticipar los riesgos financieros" (Fougère \& Solitander, 2009, p. 221) que tal amenaza entraña. Esto indica que la asunción de la RSO parte de una clara auto referencia organizacional, y no de una referencia social. En otras palabras, la organización atiende su RS en beneficio propio más que en el beneficio social extra organizacional. Este parece ser el argumento por el cual Fougère y Solitander (2009) hablan simplemente de responsabilidad organizacional, suprimiéndole la palabra social. Con esta denominación, los autores plasman la esencia de su crítica a la RSO, tal como se manifiesta en la sociedad actual.

Su crítica continúa afirmando que la verdadera intencionalidad de la RSO, en alusión implícita a los presupuestos teóricos de autores como Smith (2007), Friedman (1970) y Drucker (1984), es aportar al objetivo primordial de la organización, el cual es generar ganancias. Aún para el caso de las organizaciones no empresariales, este razonamiento puede tamizarse cambiando el 
concepto de ganancia por el de eficiencia en el manejo de los recursos. En atención a ello, la organización no asumirá comportamientos de RS si esto no contribuye, en el corto o en el largo plazo, a mantener o aumentar sus utilidades $\mathrm{o}$, incrementar su eficiencia.

Fougère y Solitander toman como referente las propuestas sobre lo que es RSO del WBSCD (2002) y la Comisión Europea (2001). Ellos vinculan la definición de las necesidades, contenidas en esas propuestas, como un problema asociado a lo referido sobre lo inconveniente de la estricta voluntariedad organizacional, en la asunción de la RSO. Este razonamiento sugiere que la organización, discrecionalmente está facultada para determinar cuáles necesidades son las importantes. Es decir, que la decisión sobre la urgencia para determinar cuáles necesidades son las importantes de una necesidad, se desplaza desde los agentes de la comunidad hacia la organización que, en cuanto nodo político de confluencia de GI, priorizará aquellas necesidades de los GI que mayor visibilidad tengan, bien sea por su acción política o por su capacidad de movilización. Si la solución de las necesidades de un GI entra en conflicto con la de otro, la organización privilegiará aquella que más aporte a la maximización de la ganancia (Fougère \& Solitander, 2009).

La más sentida de las contradicciones de la RSO es que la voluntariedad implícita supone que la organización no necesita ser regulada. Por tanto la vigilancia social y estatal son en alto grado prescindibles. La autorregulación, sumada a la ambigüedad de lo que es un acto RSO, abre un espectro amplio de acciones, con las cuales la organización puede aparecer como socialmente responsable. Esto significa que actos filantrópicos muy pequeños pueden ser suficientes para esta apariencia. Estos autores coligen, de acuerdo a la lógica sobre la que recae su crítica, que la mejor actuación, socialmente responsable, de una organización, es cumplir con sus obligaciones impositivas y con la normatividad estatal; esto marca un punto de encuentro con algunos de los fundamentos más economicistas de la RSO representados en Friedman (1970) y Drucker (1984).

En este orden de ideas, el Estado, en cuanto representante del bienestar común, es quien decide cuales necesidades sociales cubrir, y así encauzar la discrecionalidad organizacional. Pero esto supone un Estado serio y cumplidor de su función esencial, aglutinador del interés común, legislador y regulador de los actos que la sociedad demanda como socialmente responsables.

\section{Conclusión}

La actuación socialmente responsable no puede ser vista como un asunto instrumental que aporta a las ganancias organizacionales, tampoco puede ser entendida como caridad organizacional con su entorno. En realidad, la actuación de RSO corresponde al reconocimiento de la organización, como grupo social entramado en la sociedad de la cual depende.

La visión de la RSO, como elemento intermedio en los objetivos de lucro de la organización, desdibuja el discurso ético que la sustenta en su base más fundamental, y la convierte en un hecho opcional a otras alternativas estratégicas de gestión. Son estas razones las que recuerdan que el Estado debe entrar a reglamentar las manifestaciones de la RSO, con el fin de coordinar la 
actividad de las organizaciones y asegurar su compromiso, para que no atenten contra la sostenibilidad del sistema ambiental y el sistema societal.

Una mejor definición de los conceptos de la RSO es necesaria, de tal manera que se puedan definir estrategias organizacionales y de políticas públicas más precisas. De lo planteado en este artículo, se pueden extractar las siguientes recomendaciones al respecto:

1. Se deben separar los momentos de la RSO. Hablar del momento de la asunción, supone abordar la motivación que existe en los agentes sociales para empezar la RSO. El momento de la ejecución se concentraría en la definición de actos, su medición y seguimiento. Mientras el primero es, primordialmente, de naturaleza cualitativa el segundo es, a su vez, cuantitativo.

2. Es necesario estudiar la RSO como un fenómeno previo a la ganancia, lo que significa reivindicar la RSO como parte ineludible de las decisiones organizacionales, tal como sucede con los estudios financieros o las estrategias de marketing. Una organización no puede tener la RSO como acto opcional, sujeto a las disponibilidades presupuestales post ganancia, puesto que estaría encontrando en la RSO otra herramienta de marketing. La visión pre ganancia, remite obligatoriamente a la Ética en tanto disciplina de estudio de los elementos primarios de cohesión social.

3. El estudio de los factores internos de las organizaciones, no es suficiente para comprender las verdaderas implicaciones de la RSO. Recuérdese que la pena por el incumplimiento general de la RSO, es la lesión o aniquilación del sistema social y ambiental. Por ello, la RSO siempre debe ser entendida, de forma simultánea, intraorganizacionalmente y macrosocialmente. Aquí es donde entra a actuar el Estado como principal figura de la gobernanza social y como responsable de la perpetuación de una sociedad.

Actualmente se busca ampliar el panorama investigativo, con el fin de encontrar nuevas formas de medición de los alcances generales de los actos de RSO. Igualmente, se plantea la necesidad de entenderla mejor como parte la gobernanza, para lo cual se necesita seguir definiendo el papel del Estado y de la sociedad civil al respecto.

En general, la ampliación del alcance de la RSO puede erigirse sobre la base de una mejor comprensión de sus imbricaciones con las dinámicas sociales. Si se toma como referencia a la organización, la RSO se vincula con la gobernanza inter organizacional y con el Gobierno Corporativo. Así pues, se configura una cobertura investigativa mayor que la correspondiente a la surgida en la discusión sobre su voluntariedad.

\section{Referencias}

Arora, P., \& Dharwadkar, R. (2011). Corporate governance and corporate social responsibility (CSR): the moderating roles of attainment discrepancy and organization slack. Corporate governance: an international review, 19 (2), 136-152.

Assländer, M. (2011). Corporate social responsibility as subsidiary co responsibility. Journal of Business Ethics, 99, 115-128. 
Carroll, A. (1979). A three dimensional conceptual model of corporate perfomance. Academy of management review, 4(4), 497-505.

Comisión de las Comunidades Europeas. (2001). Libro verde: Fomentar un marco europeo para la responsabilidad social de las empresas. Bruselas.

Drucker, P. (1984). The new meaning of Corporate social responsibility. California Management review, 26(2), 53-63.

Egri, C., \& Ralston, D. (2008). Corporate responsibility: A review of international management research from 1998 to 2007. Journal of international management, 14, 319-339.

Enderle, G. (2010). Clarifying the terms of business ethics and CSR. Business Ethics Quarterly, 20(4), 730-732.

Fougère, M., \& Solitander, N. (2009). Against Corporate responsibility: Critical reflections on thinking, practice, content and consquences. Corporate social responsibility and enviromental Management, 16, 217-227.

Friedman, M. (13 de Septiembre de 1970). The Social Responsibility of Business is to Increase its Profits. The New York Times Magazine, pp. 122-126.

Jenkins, R. (2009). What is corporate social responsibility? En J. Peil, \& I. Van Staveren, Handbook of economics and ethics (págs. 69-76). Cheltenham (UK): Edward Elgar Publishing Limited.

Koslowski, P. (2008). Some Principles of Ethical Economy. En C. Cowton, \& M. Haase, Trends in business and economic ethics (pp. 31-70). Berlin: Springer.

Melé, D. (2007). Responsabilidad social de la empresa: una revisión crítica a las principales teorías. Revista vasca de economía Ekonomíaz, 65, 50-67.
Méndez Picazo, M. (2005). Ética y responsabilidad social corporativa. Ética y Economía ICE, (823), 141-150.

Moon, J. (2004). Goverment as a driver of Corporate social responsiblity. Nottingham: International centre for corporate social responsibliity.

Randall, D., \& Gibson, A. (1990). Methodology in business ethics research: a review and critical assesment. Journal of business ethics, 9(6), 457-471.

Sacconi, L. (2012). Corporate social responsibility and corporate governance. Econometica, 38 .

Smith, C. (2007). Bounded goodness: Marketing implications of Drucker on Corporate responsibility. Centre for Marketing Working paper, 07(104).

Taneja, S., Taneja, P., \& Gupta, R. (2011). Researches in Corporate social responsibility: A review of shifting Focus, paradigms, and methodologies. Journal of Business Ethics, 101(3), 343-364.

Tello Castrillón, C. (2006). Definición preliminar de los mecanismos de mercado y su relación con los mecanismos de no mercado. Revista venezolana de Economía $y$ ciencias sociales, 12(1), 73-99.

Ungericht, B., \& Hirt, C. (2010). CSR as a political arena: the struggle for a European framework. Business and politics, 12(4), 1-22.

Vargas Niello, J. (2006). Responsabilidad social empresarial desde la perspectiva de los consumidores.Santiago de Chile: CEPAL.

World Business Council for Sustainable Development. (2002). The business case for sustainable development WBCSD.Geneva: WBCSD. 